*Doutor em Direito pela Universidade de São Paulo (USP) Livre-docente em Direito na Universidade de São Paulo (USP) e professor no Centro Universitário Central Paulista (UNICEP) e Universidade de Ribeirão Preto (UNAERP)

E-mail: assiszanini@gmail.com

\section{Panorama do direito das coisas na Alemanha}

\section{Overview OF THE LAW OF THINGS IN GERMANY}

Leonardo Estevam de Assis Zanini*

Como citar: ZANINI, Leonardo Estevam de Assis. Panorama do direito das coisas naAlemanha. Scientia Iuris, Londrina, v. 25, n. 2 , p. 131-150, jul. 2021. DOI: $10.5433 / 21788189.2021 \mathrm{v} 25 \mathrm{n} 2 \mathrm{p} 131$. ISSN: $2178-8189$.

RESUMO: $O$ presente artigo examina o tratamento dado pelo direito alemão ao direito das coisas. Apresenta os princípios fundamentais que regem a matéria, merecendo destaque o princípio da abstração, uma peculiaridade do direito alemão que não é adotada no Brasil. Estuda a noção de coisa adotada pelo Código Civil alemão, a qual não mais se confunde com a situação dos animais. O texto ainda analisa o direito de propriedade na Alemanha, incluindo suas limitações, restrições, formas de defesa, conteúdo, bem como a vinculação social exigida pela Lei Fundamental alemã. Trata-se de pesquisa que utiliza metodologia descritiva e dedutiva, baseada fundamentalmente na investigação bibliográfica, jurisprudencial e legislativa. Por fim, o estudo panorâmico da matéria procura instigar o leitor a melhor compreender o papel socioeconômico do direito das coisas e a procurar soluções no direito alemão para problemas existentes no Brasil.

Palavras-chave: direito das coisas, direito alemão; vinculação social da propriedade; princípio da abstração; segurança jurídica.

\begin{abstract}
This article analyzes the treatment given by the German law to the rights in rem. It presents the fundamental principles that regulate the matter, highlighting the principle of abstraction, a peculiarity of German law that is not adopted in Brazil. It studies the notion of things adopted by the German Civil Code, which is no longer confused with the situation of animals. The text further analyzes property rights in Germany, including their limitations, restrictions, forms of defense, content, as well as the social link required by the German Constitution. This is a research that
\end{abstract}


uses a descriptive and deductive methodology, fundamentally based on bibliographic, jurisprudential, and legislative research. Finally, the panoramic study of the subject seeks to encourage the reader to better understand the socioeconomic role of the rights in rem and to seek solutions in German law to problems existing in Brazil.

Keywords: law of things; german law; social obligation of property; principle of abstraction; legal certainty. 


\section{INTRODUÇÃO}

O direito das coisas, em particular o direito de propriedade, tem grande significação política, econômica, social e ambiental. Nas discussões atuais sobre os valores fundamentais da democracia há especial atenção para o problema da propriedade privada e as formas como se deve lidar com ela, donde emergem questões muito sensíveis, em particular relativas à política habitacional.

$\mathrm{Na}$ Alemanha a situação não é diferente, mesmo porque o direito das coisas é um dos assuntos que guarda maior uniformidade entre os países de direito romano-germânico. Contudo, a legislação alemã apresenta algumas peculiaridades, demandando-se o estudo dos fundamentos do direito das coisas antes de uma análise mais acurada do direito de propriedade. E nesse ponto, como fruto do direito de tradição germânica, merece destaque a compreensão do princípio da abstração (Abstraktionsgrundsatz), uma peculiaridade do direito alemão, que não encontra reflexo no direito brasileiro.

Superada a análise dos fundamentos do direito das coisas e da noção de coisa adotada pelo Código Civil alemão (Bürgerliches Gesetzbuch - BGB), passa-se ao estudo do direito de propriedade, incluindo suas limitações, restrições, formas de defesa, conteúdo, bem como a vinculação social exigida pela Lei Fundamental alemã (Grundgesetz - GG).

Desse modo, o presente texto objetiva apresentar os fundamentos da legislação alemã sobre o direito das coisas. Trata-se de um estudo no qual a metodologia utilizada é descritiva e dedutiva, baseada fundamentalmente na investigação bibliográfica, jurisprudencial e legislativa. Ao mesmo tempo em que informa, o estudo panorâmico da matéria também busca instigar o leitor a procurar soluções no direito alemão para problemas existentes no Brasil. Igualmente, são feitos apontamentos específicos sobre eventuais aproximações e diferenças existentes entre o direito alemão e brasileiro, que certamente permitirão uma melhor compreensão do papel socioeconômico do direito das coisas, especialmente da propriedade.

\section{A DISTINÇÃO ENTRE DIREITOS ABSOLUTOS E DIREITOS RELATIVOS}

Os direitos subjetivos podem ser classificados de diferentes formas. A distinção mais importante na Alemanha, como também ocorre no Brasil, é entre direitos absolutos e direitos relativos.

A propriedade, no direito alemão, está protegida contra qualquer pessoa, constituindo, portanto, um direito absoluto (MEDICUS, 2010, p. 33). O oposto é o caso dos direitos que são dirigidos somente contra uma pessoa determinada e que apenas podem ser exigidos dessa pessoa, isto é, os direitos relativos, aí se incluindo os direitos obrigacionais (KLINCK, 2018, p. 1271).

Entretanto, é importante frisar que as pretensões individuais, que constituem direitos relativos, podem resultar do direito de propriedade ou de outros direitos absolutos (SCHAPP, 2010, p. 20-21). Assim, se um objeto for destruído ou danificado culposamente, o proprietário tem contra o ofensor uma pretensão ao pagamento de indenização (§ 823, 1 do BGB), que é um direito relativo (LEIPOLD, 2007, p. 72-73).

O direito alemão divide os direitos absolutos da seguinte forma: a) direitos de domínio sobre uma coisa (e.g. propriedade, penhor, usufruto); b) direitos da personalidade (direito geral da personalidade e direitos particulares da personalidade, como, por exemplo, o direito ao nome e o direito à própria imagem); c) direitos sobre bens imateriais (direitos de domínio sobre bens imateriais: direito de autor, direito de patente, direito de marca, entre outros) (LEIPOLD, 2007, p. 73).

Desse modo, tirante a relação dos direitos absolutos, da qual faz parte o direito das coisas, os demais direitos são classificados pelos alemães como direitos relativos. 


\section{A DISTINÇÃO ENTRE DIREITO DAS COISAS E DIREITO DAS OBRIGAÇÕES} obrigações.

No direito alemão também é tradicional a distinção entre direito das coisas e direito das

O direito das coisas existe sobre determinados objetos, em número limitado e somente com autorização da lei. São direitos absolutos, que devem ser respeitados por todos, pois o direito concede ampla proteção contra a sua violação por parte de terceiros (PRÜTTING, 2017, p. 8).

O direito das obrigações, por outro lado, não está limitado a determinados tipos previstos em lei, admitindo-se a sua criação em consonância com a liberdade contratual (Vertragsfreiheit). São direitos relativos, pois vinculam somente o credor e o devedor, não afetando terceiros (SCHELLHAMMER, 2017, p. 649).

Outrossim, os negócios jurídicos em matéria de direito das coisas diferem consideravelmente dos negócios jurídicos de direito das obrigações. Tanto no direito alemão como no direito brasileiro um contrato de compra e venda de uma coisa móvel, por exemplo, apenas cria para o vendedor a obrigação de transferir a propriedade do objeto da compra ${ }^{1}$.

Isso porque os negócios jurídicos obrigacionais não têm influência imediata sobre a situação jurídica de uma coisa. De fato, é imprescindível, para alterar a situação jurídica da coisa, a realização de um negócio jurídico adicional, um negócio jurídico de disposição (Verfügungsgeschäft). Assim sendo, as diferenças entre o direito das obrigações e o direito das coisas não têm natureza meramente teórica, possuindo considerável significado prático (EISENHARDT, 2018, p. 480).

Nesse ponto, vale notar que o negócio jurídico de disposição também constitui uma construção jurídica que não existe no direito brasileiro, pelo menos segundo a doutrina brasileira majoritária, o que representa um grande diferencial entre o direito das coisas na Alemanha e no Brasil (TEPEDINO; MONTEIRO FILHO; RENTERIA, 2020, p. 115).

\section{FONTES DO DIREITO DAS COISAS}

O protótipo do direito sobre uma coisa é a propriedade, a qual encontra proteção na Lei Fundamental alemã (art. 14, GG) (KÜHL; REICHOLD; RONELLENFITSCH, 2019, p. 209).

$\mathrm{O}$ direito das coisas faz parte do direito privado alemão, tanto que está previsto no terceiro livro do BGB ( $\S 854$ a 1296), intitulado "Direito das Coisas" (Sachenrecht) (BAUR; STÜRNER, 2015 , p. 5). Nele está positivado o essencial acerca das regras que regem as relações jurídicas entre um sujeito de direito (Rechtssubjekt) e uma coisa (Rechtsobjekt), o que inclui a propriedade, a posse, bem como numerosos outros direitos reais limitados (DECKENBROCK; HÖPFNER, 2017, p. 249).

Entretanto, o terceiro livro do BGB não contém todas as disposições de direito material acerca das coisas, uma vez que existem ainda normas esparsas sobre a matéria em outros livros da codificação civil (KLINCK, 2018, p. 1271). Na Parte Geral do BGB, por exemplo, existem regras sobre coisas nos $\S \S 90$ a 103, que contêm uma espécie de parte geral do direito das coisas, valendo destacar o estabelecido nos $\S \S 90$ e 90a, este último introduzido em 1990 no BGB (SCHELLHAMMER, 2017, p. 633).

Além disso, existem algumas leis especiais, bastante relevantes, que tratam de determinados assuntos de direitos das coisas fora do âmbito do BGB (BAUR; STÜRNER, 2015, p. 8). Esse é o

1 " $\$ 433$ Vertragstypische Pflichten beim Kaufvertrag. (1) Durch den Kaufvertrag wird der Verkäufer einer Sache verpflichtet, dem Käufer die Sache zu übergeben und das Eigentum an der Sache zu verschaffen. Der Verkäufer hat dem Käufer die Sache frei von Sach- und Rechtsmängeln zu verschaffen. (2) Der Käufer ist verpflichtet, dem Verkäufer den vereinbarten Kaufpreis zu zahlen und die gekaufte Sache abzunehmen”. Tradução livre: § 433 do BGB: "Deveres contratuais típicos no contrato de compra e venda. (1) Pelo contrato de compra e venda, o vendedor de uma coisa se obriga à sua entrega ao comprador e a lhe transmitir a propriedade sobre a coisa. $\mathrm{O}$ vendedor deve entregar a coisa ao comprador livre de vícios materiais e jurídicos. (2) O comprador está obrigado a pagar ao vendedor o preço de compra convencionado e a receber a coisa comprada". 
caso da lei relativa ao direito de superfície (Erbbaurechtsgesetz), da lei relativa à copropriedade em prédios de apartamentos (Wohnungseigentumsgesetz), da lei relativa a navios (Schiffsgesetz), e ainda da lei sobre minas (Bundesberggesetz) (FROMONT; KNETSCH, 2017, p. 249).

\section{A NOÇÃO DE COISA COMO OBJETO CORPORAL}

O conceito de coisa é fundamental para a compreensão do direito das coisas. Na Parte Geral do BGB, em seu $\S$ 90, encontra-se a noção de coisa (Begriff der Sache), que se entende como todo objeto corporal (körperlicher Gegenstand), tangível, que forma uma parte delimitável da matéria (SCHWAB; LÖHNIG, 2016, p. 128).

Retomando as ideias do movimento pandectista, a concepção legal alemã considera que somente as coisas corpóreas podem ser possuídas ${ }^{2}$ e que a propriedade e os direitos reais sobre coisas alheias somente podem existir sobre objetos corpóreos (CANDIAN; GAMBARO; POZZO, 1992, p. 317-318).

Com isso, fala-se em um gênero (Oberbegriff), que seria o "objeto" (Gegenstand), o qual engloba todos os objetos de direito (Rechtsobjekte), isto é, as coisas corpóreas (móveis e imóveis) e os direitos não corpóreos (LEIPOLD, 2007, p. 500). Coisas em sentido legal são então somente os bens corpóreos, concepção restrita do direito alemão, que tem sua origem na vontade dos redatores do BGB, que queriam distinguir claramente o direito das coisas do direito das obrigações (FROMONT; KNETSCH, 2017, p. 249).

Somente se considera coisa o objeto que é tangível (apreendido fisicamente), delimitável e passível de domínio (KÜHL; REICHOLD; RONELLENFITSCH, 2019, p. 209). É necessário que haja matéria no sentido físico, sendo irrelevante se a matéria está no estado sólido, líquido ou gasoso. Não é necessário então que o objeto seja sólido, pois se puder ser apreendido, qualquer que seja seu estado (sólido, líquido ou gasoso), será considerado coisa. Ainda, conforme entendimento majoritário da doutrina, o som, a eletricidade e a luz não são consideradas coisas (KALLWASS; ABELS, 2018, p. 231), pois não podem ser possuídas ou transferidas, bem como não há que se falar na existência de um direito de propriedade sobre elas (WEBER, 2015, p. 28).

Em relação ao corpo da pessoa viva, não são aplicáveis as regras relativas às coisas. $\mathrm{O}$ corpo é o suporte material do ser humano (sujeito de direito), de modo que o corpo não é ele próprio objeto de direitos de outras pessoas. Os embriões (criopreservados ou in vitro) também não são considerados coisas, não sendo objeto de propriedade (WOLF; WELLENHOFER, 2019, p. 8). No que toca ao cadáver, com exceção de múmias, esqueletos e peças anatômicas, não são aplicáveis as regras atinentes às coisas (MEDICUS, 2010, p. 480). Por outro lado, as partes separadas do corpo da pessoa viva, como o cabelo cortado ou o dente arrancado, são qualificadas como coisas (MÜLLER; GRUBER, 2016, p. 5).

Outrossim, diante dessa concepção, bens imateriais, como marcas, patentes, programas de computador, dados eletrônicos, direitos autorais, a firma (como nome do comerciante e da empresa) e o good will, não podem ser qualificados como coisas e não podem ser objeto de propriedade. São eles objetos de direito que têm grande importância prática, mas como não são corpóreos, não são coisas (LÜKE, 2018, p. 4), pois não podem ser considerados como uma parte espacialmente limitada da natureza (STRACK, 2011, p. 6).

O mesmo raciocínio se aplica aos direitos da personalidade e aos direitos de crédito (Forderungen) (FROMONT; KNETSCH, 2017, p. 250). O suporte material desses direitos, por outro lado, pode ser considerado coisa, distinção que fica clara quando se separa a propriedade do livro do direito de autor sobre o texto que ele contém (HUBMANN, 1967, p. 86).

Por conseguinte, fica evidente que a definição de coisa não busca resolver um problema de

2 No direito brasileiro não há regra tão precisa quanto a do BGB, mas, conforme a doutrina amplamente majoritária, o livro do direito das coisas é voltado para os objetos corporais (PENTEADO, 2014, p. 48). 
ordem física ou lógica, mas simplesmente atender à conveniência jurídica (SCHWAB; LÖHNIG, 2016, p. 128).

\section{OS ANIMAIS}

Os animais (Tiere) eram tidos como coisas até $1^{\circ}$ de janeiro de 1991. Atualmente não são mais coisas, devendo ser protegidos por leis especiais. A eles são aplicadas as disposições sobre coisas, por analogia, na medida em que não se estabeleça algo distinto (§ 90a do BGB) ${ }^{3}$.

A regulamentação da situação dos animais sofreu alteração legislativa, datada de 20.8.1990, tendo sido introduzido o $\S 90$ a no BGB. A codificação alemã passou então a trazer disposição especial em relação aos animais, destacando que eles não são coisas, mas que na falta de disposição especial, as regras atinentes às coisas lhes são aplicadas, conforme determina o $\S$ 90a, 3 do BGB (SCHELLHAMMER, 2017, p. 634).

Larenz e Wolf justificam a distinção de tratamento pelo fato de que os animais são seres viventes, e não meramente coisas. Desta feita, a sua configuração legal não é, em linhas gerais, a da propriedade ( $(903)$, mas sim fundada em leis especiais de proteção, o que, porém, não lhes outorga a autodeterminação e a responsabilidade próprias dos seres humanos (LARENZ; WOLF, 1997, p. 387).

Com efeito, após a referida alteração, o BGB passou a distinguir os animais (Tiere) das coisas (Sachen), considerando legalmente como coisas apenas os objetos corporais, as parcelas existentes da natureza dominável (§ 90) (BROX; WALKER, 2007, p. 400). Apesar da distinção, em realidade, no âmbito do direito civil alemão não existem disposições especiais relativas aos animais, que são tratados como coisas móveis e regidos pelas normas atinentes à propriedade e à posse (SCHWAB; LÖHNIG, 2016, p. 129).

Outrossim, vale notar que, segundo muitos estudiosos, essa alteração não passa de uma ficção, uma banalidade, decorrente de motivação política, que procurou implantar a pauta de proteção dos animais no âmbito do BGB. A alteração é realmente objeto de fortes críticas na Alemanha, afirmando-se que, no fim das contas, os animais continuam tendo tratamento como coisas na esfera do direito civil (KÜHL; REICHOLD; RONELLENFITSCH, 2019, p. 210).

Em todo caso, como alerta Medicus (2010, p. 480), é um absurdo a pretensão de dar tratamento aos animais como sujeitos jurídicos ${ }^{4}$. E para reforçar seu entendimento, exemplifica com um pedido teratológico de chamamento de focas para participação em um litígio administrativo sobre a poluição do Mar do Norte.

\section{COISAS MÓVEIS E IMÓVEIS}

Seguindo a tradição existente no direito dos países de civil law, o Código Civil alemão distingue as coisas móveis (bewegliche Sachen - Mobilien) das coisas imóveis, ou terrenos (Grundstücke - Immobilien) (LÜKE, 2018, p. 10). Isso tem bastante relevância, pois, tal como se passa no direito brasileiro, o regime jurídico dos móveis e imóveis é diverso, particularmente no que toca à sua forma de transferência (EISENHARDT, 2018, p. 482).

Com efeito, ao reconhecer a summa divisio entre as coisas móveis e imóveis, a doutrina alemã divide o direito das coisas em dois grandes blocos, chegando-se, inclusive, a falar na

3 Tradução livre do $\S 90$ a do BGB: “Animais não são coisas. Eles são protegidos por leis especiais. Até onde não for diversamente determinado, a eles são aplicáveis os correspondentes preceitos válidos para as coisas".

4 No Brasil, a despeito de algumas decisões isoladas, é certo que a legislação considera os animais como coisas, ou melhor, como semoventes (art. 82 do Código Civil). Não se pode negar, entretanto, que muitos animais, especialmente os mamíferos, devem ser considerados como seres sencientes, o que demandaria uma revisão na legislação brasileira. Nessa linha, o caminho adotado pelo BGB parece ser o mais salutar, uma vez que os animais foram excluídos da categoria das coisas, mas continuam sendo objetos de direito, isto é, os animais não pertencem à categoria dos sujeitos de direito (WOLF; NEUNER, 2016, p. 301-302). 
existência de um direito das coisas móveis (Mobiliarsachenrecht) e de um direito das coisas imóveis (Immobiliarsachenrecht) (WOLF; WELLENHOFER, 2019, p. 7). E nessa linha, os estudiosos alemães se encarregam de distinguir as duas categorias, uma vez que a legislação não traz maiores esclarecimentos (BAUR; STÜRNER, 2015, p. 12).

Em face da ausência de definição legal, para que se compreenda a distinção, faz-se mister que se parta do conceito de coisa imóvel. Apesar de não ser expressamente consagrada pelos $\S \S 93$ a 98 do BGB, a doutrina define coisa imóvel como "uma parte delimitada da superfície terrestre que está registrada no registro imobiliário como uma parcela independente" (KÜHL; REICHOLD; RONELLENFITSCH, 2019, p. 210). Trata-se de um conceito técnico-jurídico que é compreendido a partir do conteúdo do registro imobiliário (Grundbuch). Assim sendo, a ideia de Grundstück não coincide com a repartição do solo na natureza (BAUR; STÜRNER, 2015, p. 12).

De fato, todo o território alemão está dividido em parcelas cadastrais. Os terrenos (Grundstück) são criados a partir de um ou mais lotes. O Registro Imobiliário fornece as informações sobre se uma parcela ou se várias parcelas constituem um imóvel (SCHWAB; LÖHNIG, 2016, p. 131).

Nesse ponto, o Código Civil alemão, diferentemente do direito brasileiro ${ }^{5}$, utiliza para determinar a categoria dos imóveis a noção de terreno (Grundstück). Ao lado dos terrenos propriamente ditos, a noção de coisa imóvel também abrange as coisas móveis que se tornaram suas partes constitutivas essenciais (wesentliche Bestandteile), cuja previsão consta dos $\S \S 93$ e 94 do BGB (SCHELLHAMMER, 2017, p. 635). Desse modo, todos os demais objetos que não constituam um terreno ou uma parte constitutiva essencial do terreno são considerados coisas móveis (WOLF; NEUNER, 2016, p. 302).

O direito alemão, somente de forma excepcional, admite a dissociação da propriedade imobiliária entre o terreno e o edifício (ZANINI, 2016, p. 46), como acontece na legislação relativa ao direito de superfície (Erbbaurecht).

Por conseguinte, de forma residual, toda coisa corpórea que pode mudar sua posição espacial, bem como que não se classifique como imóvel (Grundstück), é considerada uma coisa móvel (BAUR; STÜRNER, 2015, p. 12). Em contraposição, as coisas imóveis têm definição técnico-jurídica e não podem mudar a sua localização espacial (WOLF; NEUNER, 2016, p. 302).

\section{PRINCÍPIOS FUNDAMENTAIS DO DIREITO DAS COISAS}

O direito das coisas é regido por determinados princípios fundamentais, que não são expressamente mencionados pela legislação alemã. Como tais princípios orientam a utilização e a interpretação das disposições sobre a matéria, seu conhecimento é muito importante (WOLF; WELLENHOFER, 2019, p. 27).

A seguir será feita uma breve exposição sobre os seguintes princípios: a) taxatividade; b) publicidade; c) especialidade; d) abstração e separação. Entre os princípios fundamentais do direito das coisas também se inclui o caráter absoluto (Absolutheit), que já foi tratado anteriormente.

\subsection{NuMERUS CLAUSUS DOS DIREITOS REAIS}

Como sucede nos países do ramo da civil law, o direito alemão também adota o princípio de que os direitos reais são enumerados de forma limitada pela lei, a qual também determina o conteúdo e a forma de transmissão desses direitos (SCHELLHAMMER, 2017, p. 651).

5 Conforme ensina Lôbo, o bem imóvel pode ser definido, no direito brasileiro, como "a parte da superfície da terra, chão ou solo, e tudo o que se edifique sobre ela ou se incorpore em caráter permanente, pela mão do homem ou pela natureza" (LÔBO, 2018). 
O numerus clausus dos direitos reais tem então dois significados: a) Typenzwang, isto é, as partes não podem criar novos direitos reais, uma vez que esses direitos somente podem ser criados por lei (LÜKE, 2018, p. 12); b) Typenfixierung, ou seja, o conteúdo dos direitos reais é fixado pela lei (KLUNZINGER, 2013, p. 631), não se admitindo que seja alterado por negócio jurídico (BREHM; BERGER, 2014, p. 22). E isso ocorre pelo fato de que os direitos reais têm efeitos erga omnes, o que demanda que sejam conhecidos e previamente definidos de forma clara e sempre reconhecível (BÄHR, 2013, p. 423).

Com efeito, em virtude do princípio do numerus clausus, as partes não podem criar um direito real novo, desconhecido por terceiros, nem alterar o conteúdo de um direito real existente. Os direitos reais são então apenas aqueles determinados pela lei e o contorno desses direitos também deve ser estipulado pela lei (BREHM; BERGER, 2014, p. 22).

O princípio da tipologia imperativa (Typenzwang des Sachenrechts) se opõe à liberdade das partes em matéria contratual (Vertragsfreiheit), largamente aplicado no âmbito do direito das obrigações. Há então limites muito mais estreitos no âmbito do direito das coisas do que no direito das obrigações (FÖRSCHLER, 2018, p. 140). Consequentemente, o direito das coisas é constituído, predominantemente, por normas cogentes (zwingendes Recht) (EISENHARDT, 2018, p. 481).

Em todo caso, a lista dos direitos reais prevista pelo BGB é muito próxima daquela constante do art. 1.225 do Código Civil brasileiro. E o mesmo pode ser dito em relação à forma de atuação do princípio da taxatividade, que guarda bastante semelhança com o que ocorre no direito pátrio (ZANINI, 2020, p. 16-18).

\subsection{PrincíPIO da PUbLiCIDAde}

O direito alemão estabelece que as relações jurídicas atinentes a direitos das coisas devem estar acompanhadas de medidas que permitam levar ao conhecimento de terceiros a sua existência. Isto é, a lei exige que os negócios jurídicos no âmbito do direito das coisas devem ser visíveis externamente (BAUR; STÜRNER, 2015, p. 38).

De acordo com o princípio da publicidade (Publizitätsgrundsatz), a constituição, a modificação, a transmissão e a extinção de direitos das coisas devem ser realizadas por meio de ato jurídico dotado de visibilidade exterior (Publizitätsmittel), que permita a qualquer pessoa conhecer a existência de direitos sobre determinada coisa (FROMONT; KNETSCH, 2017, p. 252).

A publicidade do direito das coisas determina o modo como se dará a sua transmissão (Übertragungswirkung), possibilita a aquisição a non domino (Gutglaubenswirkung) e ainda fundamenta uma presunção legal em favor dos direitos das coisas (Vermutungswirkung) (LÜKE, 2018, p. 13).

Como regra, tal visibilidade é assegurada, em matéria imobiliária, pela inscrição no livro de registro imobiliário (Grundbuch), conforme dispõe o $\S 930$ do BGB. No que toca aos bens móveis, a publicidade ocorre pela transferência da posse (§ 929 do BGB), isto é, pela tradição (Übergabe) (MEDER; CZELK, 2018, p. 6).

Em todo caso, vale frisar que no sistema econômico atual a posse sofreu forte perda de sua função como meio de publicidade, uma vez que muitos bens jurídicos são usados por possuidores que não são proprietários, o que ocorre quando se está diante de figuras como o leasing, a reserva de domínio (Eigentumsvorbehalt) ou a propriedade fiduciária (Sicherungseigentum) (WOLF; WELLENHOFER, 2019, p. 29).

\subsection{PrincíPIO DA ESPECIALIDAde}

Como se sabe, uma das principais tarefas do direito das coisas é a ligação de um sujeito de 
direito a um objeto jurídico. Para tanto, a titularidade sobre uma coisa deve estar clara e inequívoca, exigência que está em consonância com a segurança jurídica. Um negócio jurídico de direito das coisas somente é eficaz se a coisa em questão for determinada de forma inequívoca, isto é, especializada (KÜHL; REICHOLD; RONELLENFITSCH, 2019, p. 213).

O princípio da especialidade (Spezialitätsgrundsatz ou Bestimmtheit) é bastante importante e significa que o direito das coisas deve incidir somente sobre uma coisa individualizada (FÖRSCHLER, 2018, p. 139). Em toda transferência é necessário que o seu objeto seja precisamente designado, de forma que seja possível distingui-lo de outras coisas (SCHELLHAMMER, 2017, p. 650).

Outrossim, é importante observar que o BGB ignora a existência de direito das coisas sobre universalidades (Sachgesamtheiten). Com isso, um conjunto de coisas e de direitos, como um fundo de comércio, não pode ser objeto de um mesmo direito das coisas. Sua transmissão não poderá ser feita senão organizando a transferência da propriedade de cada coisa pertencente à universalidade (FROMONT; KNETSCH, 2017, p. 249). Desse modo, é necessário elaborar um inventário com todos os bens individualizados (MEDER; CZELK, 2018, p. 7). E nesse ponto o direito alemão certamente é mais exigente que o direito brasileiro.

Por conseguinte, uma pessoa deve ser capaz de identificar, com base somente no negócio jurídico de disposição, quem tem o direito real sobre determinada coisa (LÜKE, 2018, p. 12).

\subsection{PrincíPIOS da ABSTRaÇão E da SEPARAÇÃo}

O direito alemão apresenta uma grande particularidade que é a adoção dos princípios da abstração e da separação (Trennungs- und Abstraktionsprinzip). Entre os países do sistema da civil law, a Alemanha, por influência de Savigny, tomou um caminho bastante peculiar, consagrando os princípios da abstração e da separação, o que gera bastante dificuldade de compreensão por parte dos estudiosos estrangeiros (DECKENBROCK; HÖPFNER, 2017, p. 31).

A matéria está regulada na Parte Geral do BGB, pois diz respeito à noção geral de negócios jurídicos. Assim sendo, o direito alemão realiza distinção bastante nítida entre dois tipos de negócios jurídicos, isto é, os negócios criadores de obrigações (Verpflichtungsgeschäfte) e os negócios de disposição (Verfügungsgeschäfte) (WOLF; WELLENHOFER, 2019, p. 32). Tal distinção corresponde ao princípio da separação (Trennungsprinzip), que é um pressuposto necessário para a existência do princípio da abstração (Abstraktionsprinzip) (LEIPOLD, 2007, p. $81)$.

De fato, a transferência da propriedade, seja de um móvel ou de um imóvel, não se opera no âmbito do contrato de compra e venda (Kaufvertrag), que não tem qualquer efeito translativo, criando apenas obrigações ( $§ 433$ do BGB). Para que ocorra a transferência da propriedade é imprescindível a realização de um negócio jurídico distinto, um segundo negócio jurídico, ainda que tal negócio seja frequentemente celebrado simultaneamente com o contrato que cria as obrigações (WITZ, 2018, p. 113). Esse acordo de vontades, que tem como objetivo a transferência da propriedade, é denominado Einigung. Em matéria imobiliária a Einigung é feita diante de uma autoridade competente, normalmente um notário, recebendo denominação específica de Auflassung (PRÜTTING, 2017, p. 144-145).

Ademais, para que a transferência se concretize, além da Einigung, é necessário um ato real que dê publicidade à transferência. No caso de coisas móveis esse ato real é a entrega do bem ao seu adquirente, isto é, a tradição (Übergabe, § 929 do BGB). Em relação às coisas imóveis, a transferência se conclui com a inscrição da mudança da situação jurídica no registro imobiliário (Eintragung im Grundbuch, $\S 873$ do BGB) (MEDER; CZELK, 2018, p. 178).

Desse modo, o princípio da separação, que encontra suas raízes no direito romano, significa, para o direito alemão, a existência de dualidade de negócios jurídicos, isto é, um negócio 
jurídico obrigacional, que pode ser uma compra e venda, e um negócio jurídico de disposição, a Einigung (PIETREK, 2015, p. 29-30).

No direito brasileiro também se admite a existência do princípio da separação, mas em um sentido um pouco diverso, visto que, da mesma forma que no direito alemão, o negócio jurídico obrigacional não transfere a propriedade, uma vez que é necessária a realização de um ato real, que pode ser a tradição ou o registro no cartório de registro de imóveis. E nesse ponto, é importante que fique claro que no direito brasileiro não se exige um segundo negócio jurídico, o negócio jurídico de disposição, que como foi visto, recebe no direito alemão o nome de Einigung.

Ao lado do princípio da separação, a doutrina alemã desenvolveu no século XIX o princípio da abstração. Savigny é considerado o responsável pela elaboração do modelo alemão da abstração, cujo objetivo seria garantir maior segurança jurídica (Rechtssicherheit) (KÜHL; REICHOLD; RONELLENFITSCH, 2019, p. 212).

Pelo princípio da abstração, o negócio jurídico obrigacional é independente do negócio jurídico de disposição (LEIPOLD, 2007, p. 81), de maneira que eventuais problemas relacionados com o negócio jurídico obrigacional (e.g. nulidades, vícios de consentimento etc.) não afetam o negócio jurídico de disposição, que permanece eficaz ${ }^{6}$. É juridicamente irrelevante a causa da transferência, não interessa se foi feito, por exemplo, um contrato de doação ou uma compra e venda.

A doutrina alemã divide a abstração em dois aspectos. Por um lado, o negócio jurídico real não depende da existência de uma causa (inhaltliche Abstraktion) (LÜKE, 2018, p. 15). Por outro lado, o negócio jurídico real é independente do negócio jurídico obrigacional (äußerlich Abstraktion) (BAUR; STÜRNER, 2015, p. 55).

Ademais, como os atos de disposição são abstratos, as ações fundadas em enriquecimento sem causa ( $\S \S 812$ e seguintes do BGB) ganham bastante importância no direito alemão, visto que são ajuizadas pelo alienante para a obtenção da devolução da coisa, o que será possível, a menos que a coisa tenha sido transferida nesse entretempo a um terceiro.

Todavia, existem casos em que a mesma causa pode gerar a nulidade tanto do negócio jurídico obrigacional como do negócio jurídico de disposição (Fehleridentität) (LEIPOLD, 2007, p. 81). Isso ocorre, como regra, tanto em matéria de incapacidade jurídica (Mängel der Geschäftsfähigkeit) como em caso de dolo ou de coação ilegítima. A situação é, entretanto, diferente na hipótese de erro. Realmente, como o único objetivo do negócio jurídico de disposição é provocar a transferência da propriedade, geralmente ele não é afetado por erros cometidos quando o negócio gerador da obrigação é celebrado. Ademais, a apreciação da extensão da nulidade a ambos os negócios jurídicos (obrigacional e real), em caso de violação da moral ( $\$ 138$ do BGB) ou de proibição legal (§ 134 do BGB), exige uma apreciação caso a caso (WITZ, 2018, p. 114).

Vale notar, outrossim, que a categoria dos negócios abstratos é mais ampla do que a dos negócios de disposição, visto que todos os negócios de disposição são negócios abstratos, mas a recíproca não é verdadeira (WITZ, 2018, p. 114).

Em suma, pelo princípio da separação, o negócio de direito obrigacional e o negócio de disposição devem ser estritamente separados um do outro. Pelo princípio da abstração, o negócio jurídico de disposição não depende de causa e sua eficácia permanece inalterada, não obstante o negócio de direito obrigacional se apresentar defeituoso (KÜHL; REICHOLD; RONELLENFITSCH, 2019, p. 212). Assim sendo, a separação entre direitos obrigacionais e direitos das coisas é expressão dos princípios da separação e da abstração (ROBBERS, 2017, p. 183).

6 No direito brasileiro, por outro lado, como não foi acolhido o princípio da abstração, o negócio jurídico que deu origem ao registro é indispensável para a apuração de sua validade (TEPEDINO; MONTEIRO FILHO; RENTERIA, 2020, p. 115). 


\section{O DIREITO DE P]ROPRIEDADE}

O BGB não apresenta uma definição legal do direito de propriedade (EISENHARDT, 2018, p. 489). Apesar disso, a propriedade é conceituada pela doutrina como a forma mais abrangente de atribuição legal de uma coisa ao patrimônio de um sujeito de direito (BÄHR, 2013, p. 438). É um direito ilimitado no tempo e confere um senhorio pleno sobre a coisa (FROMONT; KNETSCH, 2017, p. 258). Como no direito brasileiro, o direito de propriedade é, no direito alemão, o direito real mais importante e mais completo.

A redação do $\S 903$ do BGB não deixa dúvidas ao estabelecer que o proprietário pode, na medida em que a lei ou direitos de terceiros não se oponham, comportar-se em relação à coisa (móvel ou imóvel) como ele entender, excluindo toda ingerência alheia (LEIPOLD, 2007, p. 63).

Tal concepção, que remonta ao direito romano, remete à distinção de duas estruturas no direito de propriedade: a) uma positiva, que permite ao proprietário se comportar como entender em relação à coisa (mit der Sache nach Belieben verfahren) (LÜKE, 2018, p. 46); b) uma negativa, que tem função de exclusão (andere von jeder Einwirkung ausschließen), isto é, afastar terceiros de atuar em relação à coisa (STAUDINGER; WESTERMANN, 2017, p. 23).

Considerando a estrutura formal da propriedade, o proprietário pode fazer tudo com a coisa, são os poderes positivos (Positive Befugnisse): ele pode perceber os frutos ou renunciá-los, pode fruir da coisa pessoalmente ou permitir que um terceiro o faça, bem como pode livremente aliená-la ou simplesmente gravá-la ${ }^{7}$. Ao lado dessa dimensão positiva, o direito de propriedade confere também poderes negativos (Negative Befugnisse). Assim, os terceiros são excluídos de todos os direitos sobre a coisa ( $\$ 903$ do BGB), salvo permissão do proprietário (MÜLLER; GRUBER, 2016, p. 22).

A plenitude do direito de propriedade não é, entretanto, absoluta. Desse modo, a propriedade confere atualmente não somente direitos, mas também deveres, o que se confirma pelo estudo da posição e da tutela do direito de propriedade no direito alemão (MEDER; CZELK, 2018, p. 42).

\section{A PROTEÇÃO CONSTITUCIONAL DO DIREITO DE PROPRIEDADE E A PROPRIEDADE DO CÓDIGO CIVIL ALEMÃO}

A Lei Fundamental de Bonn (Grundgesetz für die Bundesrepublik Deutschland), promulgada no dia 23 de maio de 1949, considerando a vital importância que a propriedade tem para a sociedade, incluiu-a entre os direitos fundamentais, conforme expresso no art. 14, alínea 1 (EISENHARDT, 2018, p. 488-489).

A propriedade foi então garantida expressamente pelo art. 14, alínea 1 da Lei Fundamental, que determinou a forma como os bens, necessários à sobrevivência, devem ser distribuídos e utilizados $^{8}$. De fato, conforme a Corte Constitucional Federal (Bundesverfassungsgericht), a Lei Fundamental permite a todos criar um espaço de liberdade em termos de patrimônio e, consequentemente, um ambiente de vida sujeito à sua própria responsabilidade (KINGREEN; POSCHER, 2013, p. 242).

A proteção constitucional do direito de propriedade implica, por um lado, o direito de se opor às ingerências das autoridades públicas (Abwehrrecht ou Schutzfunktion), o que constitui uma garantia individual (Individualgarantie). Por outro lado, reconhece-se a propriedade como

$7 \mathrm{Na}$ doutrina se afirma que o proprietário pode se abster de qualquer uso ou destruir a coisa. No entanto, isso é relativizado, visto que existe a vinculação social da utilização da propriedade (BÄHR, 2013, p. 438). Schwab e Löhnig lembram que o $\S 903,1$ do BGB apresenta a estrutura formal da propriedade (die formale Struktur des Eigentums), a qual não está em conflito com a vinculação social da propriedade (SCHWAB; LÖHNIG, 2016 , p. 127).

8 Tradução livre do artigo 14, alínea 1 da Lei Fundamental: "A propriedade e o direito de sucessão são garantidos. Seus conteúdos e limites são definidos por lei”. 
uma garantia institucional (Institutsgarantie), isto é, a propriedade é garantida como um instituto jurídico, atribuindo-se à lei a fixação de seu conteúdo e dos seus limites (MÜLLER; GRUBER, 2016, p. 21). O Estado é então obrigado a criar um sistema jurídico que assegure a aplicabilidade prática da propriedade, que permita ao indivíduo adquirir a propriedade e a utilizá-la de forma que o conteúdo essencial desse direito seja preservado. E nesse ponto o BGB é uma das mais importantes leis de aplicação do art. 14, 1 da Lei Fundamental (BÄHR, 2013, p. 439).

Todavia, a garantia institucional da propriedade privada não é absolutamente intangível, reconhecendo-se a existência de limites impostos pelo direito privado e pelo direito público. $\mathrm{O}$ art. 15 da Lei Fundamental, por exemplo, permite ao Estado coletivizar o solo, os recursos naturais e os meios de produção9. No entanto, a expropriação apenas pode ter lugar em benefício da coletividade e somente pode ser feita por lei ou com base em autorização legal (LEIPOLD, 2007, p. 64). Assim sendo, a lei de desapropriação regula o tipo e a extensão da indenização, objetivando assegurar que o prejudicado seja adequadamente compensado pelo que perdeu (STAUDINGER; WESTERMANN, 2017, p. 25).

Outrossim, vale frisar que a concepção constitucional de propriedade abrange não somente a propriedade de coisas, mas também a titularidade de todos os direitos patrimoniais (LEIPOLD, 2007, p. 63). Desse modo, o campo de aplicação da proteção constitucional do direito de propriedade é mais amplo do que aquele fixado pelo direito privado no $\S 90$ do BGB, que define a coisa como objeto corporal (körperliche Gegenstände) (EISENHARDT, 2018, p. 489-490). No âmbito da propriedade constitucional incluem-se, por exemplo, pretensões creditícias, direitos autorais (Urheberrecht), propriedade industrial (Gewerblicher Rechtsschutz) etc.

Em contraposição, no sentido mais restrito dado pelo BGB, não existe propriedade sobre direitos, mas sim titularidade (Inhaberschaft) (FÖRSCHLER, 2018, p. 122). Isso significa que alguém pode ser titular de uma patente, mas não proprietário da patente, visto que só existe propriedade sobre objetos corpóreos (PRÜTTING, 2017, p. 119).

\section{O CONTEÚDO E OS LIMITES DA PROPRIEDADE CONSTITUCIONAL}

A Lei Fundamental garante o direito de propriedade e também estabelece que o conteúdo e os limites desse direito serão fixados por lei (art. 14, alínea 1 da Lei Fundamental), o que permite ao legislador restringir seus atributos. A jurisprudência constitucional subordina estas restrições, como acontece com qualquer direito fundamental, a um teste de proporcionalidade, que é mais rigoroso quando a restrição afeta o patrimônio adquirido pela força de trabalho do que quando diz respeito a bens imóveis ou meios de produção (FROMONT; KNETSCH, 2017, p. 259).

Nesse contexto, a liberdade do proprietário não é ilimitada. A visão liberal do direito de propriedade como um direito absoluto foi limitada pelo reconhecimento de sua dimensão social. Influenciada por uma disposição da Constituição de Weimar, o art. 14, alínea 2 da Lei Fundamental estabelece: "A propriedade obriga. Seu uso deve servir, ao mesmo tempo, ao bem comum". Assim sendo, tal disposição constitucional deixa claro que a propriedade não é somente um direito, mas também um dever (MEDER; CZELK, 2018, p. 43).

Além das disposições da Lei Fundamental, existem muitas regras que limitam o direito de propriedade no BGB. O texto do $\S 903,1$ indica, por exemplo, que o direito de propriedade, em particular no que diz respeito à extensão do poder de usar, tem limites que resultam do dever cívico geral do proprietário de levar em consideração os interesses de outras pessoas, os interesses da comunidade, bem como as restrições à propriedade acordadas pelo próprio proprietário (BÄHR,

9 O artigo 15 da Lei Fundamental parece, a primeira vista, algo estranho ao espírito da Lei Fundamental. Ele foi inserido nos trabalhos preparatórios em razão da insistência do partido social democrata, que desejava deixar a porta aberta para uma socialização dos bens de produção. Embora nunca tenha sido aplicado na prática, foi possível considerar a utilização desse artigo durante a crise bancária de 2008 e 2009, para salvar determinadas instituições de crédito. 
2013, p. 440). O $\S 906$, por sua vez, impõe ao proprietário um certo grau de tolerância em face de perturbações da vizinhança. A lei sobre urbanismo condiciona a construção de um edifício à obtenção de uma licença de construção emitida pela autoridade pública ${ }^{10}$. Ademais, existem outras limitações para garantir a proteção do ambiente, organizar a caça e a pesca (Bundesjagdgesetz - BjagdG), regular a exploração dos recursos do solo (Bundesberggesetz - BbergG) e das águas superficiais ${ }^{11}$.

Por conseguinte, ao lado dos limites impostos pelo respeito dos direitos de terceiros, atualmente também existem inúmeras disposições de direito público que limitam a propriedade (LEIPOLD, 2007, p. 64).

\section{VINCULAÇÃO SOCIAL DA PROPRIEDADE}

O princípio geral é que a utilização da propriedade não deve satisfazer apenas as necessidades egoístas do titular do direito (art. 14, inciso 2 da Lei Fundamental). A utilização da propriedade obriga e deve, ao mesmo tempo, servir ao bem comum (FÖRSCHLER, 2018, p. 122). Isso significa que o $\S 903$ do BGB expressa apenas a estrutura formal da propriedade, que não pode contrariar a sua vinculação social (SCHWAB; LÖHNIG, 2016, p. 127).

$\mathrm{O}$ direito de propriedade está assim sujeito a uma obrigação social, que permite ao legislador, mesmo sem expropriação formal, estabelecer limites à utilização da propriedade, o que está em consonância com os valores de um Estado de direito democrático e social (BÄHR, 2013, p. 440).

No que toca aos imóveis, os exemplos de vinculação social da propriedade (Sozialbindung des Eigentums) são particularmente numerosos: eles vão desde a regulamentação da liberdade de construção e seus limites, passando por regulamentos de proteção do meio ambiente, do patrimônio histórico e artístico, chegando até mesmo à regulamentação da locação de imóveis residenciais e ao arrendamento de espaços utilizados para produção empresarial. Nessa linha, poderia ser determinado, por exemplo, o plantio de vegetação em um terreno à margem de um rio para reduzir o risco de inundação. E nesse caso, se a intervenção for proporcional ao risco, o proprietário deve tolerar tal interferência das autoridades em sua propriedade, mas, dependendo da situação, terá direito a uma indenização (MEDER; CZELK, 2018, p. 43).

De qualquer forma, considera-se que é bastante difícil estabelecer, em casos concretos, a fronteira entre a concretização jurídica da vinculação social da propriedade (sem pagamento de indenização) e a desapropriação (com necessidade de pagamento de indenização). A temática continua controversa na jurisprudência do Tribunal Constitucional Federal e dos Tribunais Federais Superiores, mesmo já passados 60 anos da entrada em vigor da Lei Fundamental. A dificuldade reside no fato de que não só os atos diretos do Poder Executivo voltados à privação individual de direitos conduzem à desapropriação. Também as restrições da propriedade através de regulamentos normativos abstratos têm um efeito direto sobre a livre utilização da propriedade (e.g. tombamento de todo um bairro urbano como zona histórica protegida, pelo que os edifícios aí situados só podem ser estruturalmente alterados em conformidade com as normas de preservação de monumentos) (BÄHR, 2013, p. 440).

Vale ainda frisar que os alemães, diferentemente do que se tem visto no Brasil, são bastante cautelosos em relação à intervenção na propriedade, o que somente é permitido quando preenchidos determinados pressupostos, como a existência de uma exceção prevista pela lei e para

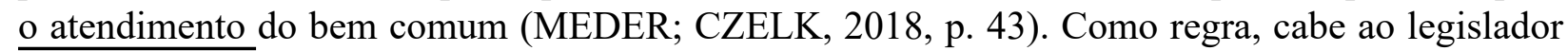

10 As condições de obtenção de uma licença de construção estão previstas nos códigos de construção dos Estados (Landesbauordnungen).

11 Pode-se mencionar, como exemplo, a lei federal relativa à proteção contra a poluição e os incómodos (Bundesimmissionsschutzgesetz - BimmSchG). O texto dessa lei exige que o operador de uma instalação perigosa obtenha uma autorização administrativa prévia (Genehmigung). 
fixar a amplitude da vinculação social da propriedade, restando tal tarefa aos tribunais somente em situações muito excepcionais (SCHWAB; LÖHNIG, 2016, p. 127).

Por derradeiro, vale observar que a doutrina alemã não coloca a vinculação social como integrante do próprio conteúdo do direito de propriedade, como fazem muitos autores brasileiros ${ }^{12}$. No direito alemão o tema é tratado no âmbito dos limites ao direito de propriedade.

\section{RESTRIÇÕES VOLUNTÁRIAS À PROPRIEDADE}

O proprietário pode, por meio de negócios jurídicos com terceiros, restringir o seu direito à livre utilização ou exploração do objeto que lhe pertence. Essa restrição pode decorrer de negócios jurídicos de direito obrigacional, como contratos, nos quais o proprietário se compromete a se abster de determinada utilização da coisa ou a colocar a utilização da coisa à disposição do parceiro contratante (BÄHR, 2013, p. 441).

Por outro lado, o proprietário também pode transferir temporariamente os poderes de utilização e de fruição para criar direitos reais limitados, que vão existir paralelamente ao seu direito de propriedade. Nessa situação, o poder do proprietário de agir como bem entender em relação à coisa fica limitado pelos direitos de terceiros que ele próprio (proprietário) criou. Isso ocorre quando, por exemplo, o proprietário de uma casa concede a outra pessoa o direito real de habitação sobre o edifício, ou partes dele, de maneira que essa pessoa poderá utilizar e possuir o imóvel (§ 1093 do BGB) (BÄHR, 2013, p. 441).

Em todo caso, é muito diferente a situação quando há transferência dos poderes do proprietário pela via do direito das obrigações ou dos direitos reais. De fato, os direitos reais limitados têm um significado especial, visto que têm precedência sobre as disposições subsequentes do proprietário da coisa, isto é, a parte que adquiriu um direito real sobre a propriedade alheia poderá fazer valer esse direito mesmo contra um sucessor posterior do proprietário. Nas relações estabelecidas apenas com força de direito obrigacional, por outro lado, o titular de um direito somente poderá exercê-lo diante do sujeito com quem entabulou o vínculo obrigacional, visto que se trata de um direito relativo. Caso o direito de propriedade seja transferido a um terceiro ou se um terceiro ajuizar uma ação contra o proprietário, não será possível opor a existência da relação obrigacional àquele que não figurava como parte nela (BÄHR, 2013, p. 441).

\section{DIFERENTES FORMAS DE PROPRIEDADE}

Ao lado da propriedade individual (Alleineigentum), o direito alemão também admite que a propriedade possa ser partilhada entre várias pessoas. Sobre o tema, o BGB reconhece formas diversas para a regulamentação das relações jurídicas externas e internas decorrentes da copropriedade: a) a copropriedade por frações (Miteigentum nach Bruchteilen); b) a copropriedade de mão comum (Gesamthandseigentum) (MUSIELAK; HAU, 2019, p. 289).

$\mathrm{Na}$ copropriedade por frações ( $\S \S 1008$ e seguintes do BGB), salvo disposição em contrário, os coproprietários detêm uma parte abstrata de um bem, uma cota-parte ideal, que pode ser livremente cedida e que representa a parte do valor que caberia a cada um dos coproprietários em caso de divisão (WOLF; WELLENHOFER, 2019, p. 16).

A copropriedade por frações, que no Código Civil brasileiro é chamada de condomínio geral (art. 1.314 e seguintes), é a figura mais comum no direito alemão. Ela sempre ocorre quando várias pessoas adquirem uma coisa sem estarem ligadas entre si por um vínculo de mão comum. Entretanto, o proprietário único de uma coisa também pode concedê-la a outra pessoa, em um negócio de disposição, passando ambos a serem coproprietários (BÄHR, 2013, p. 442).

12 Nessa linha, adverte Lôbo que na "contemporaneidade, a função social afastou-se da concepção de limites externos, passando a integrar os próprios conteúdos da propriedade e da posse” (LÔBO, 2020, p. 129). 
A copropriedade de mão comum (Gesamthandseigentum) é outra forma de copropriedade reconhecida pelo direito alemão ${ }^{13}$. Nela cada um tem simultaneamente a propriedade de toda a coisa, não existindo a propriedade de frações ideais. Ela surge nos casos em que vários sujeitos de direito formam uma comunhão patrimonial com base em relações jurídicas pessoais especiais. O BGB conhece somente três tipos dessa forma de copropriedade: a) a comunidade de sucessores (Erbengemeinschaft - § 2032 do BGB); b) a comunhão entre esposos (eheliche Gütergemeinschaft $\S 1416$ do BGB); c) a sociedade de pessoas (Gesellschaftsvermögen - $§ 718$ do BGB) (MUSIELAK; HAU, 2019, p. 289).

A diferença essencial da copropriedade por frações em relação à copropriedade de mão comum é que nesta os coproprietários estão impossibilitados de dispor de sua parte abstrata sem o consentimento dos outros (WOLF; WELLENHOFER, 2019, p. 17).

Por derradeiro, vale frisar que o condomínio edilício é uma forma especial de copropriedade, que surge, conforme o $\S 10,1$ da Lei de Condomínios Edilícios (Wohnungseigentumsgesetz WEG), pela existência de propriedade particular (Alleineigentum) sobre uma habitação em conexão com a propriedade por frações (Bruchteilseigentum) sobre as áreas comuns (FÖRSCHLER, 2018, p. 124).

\section{A PROTEÇÃO DO DIREITO DE PROPRIEDADE}

Como um direito absoluto, a propriedade sobre uma coisa é protegida contra todos. A salvaguarda da propriedade privada contra medidas tomadas pelo Estado encontra previsão no art. 14 da Lei Fundamental. Já a tutela da propriedade contra a interferência de outros particulares é regida pelo direito civil (EISENHARDT, 2018, p. 490).

Para tanto, o BGB permite ao proprietário a utilização de pretensões de defesa, de restituição e de indenização contra os atos não autorizados de terceiros que violem o direito de propriedade. Ainda, considerando que no direito alemão, como no brasileiro, o proprietário pode ser possuidor (direto ou indireto) da coisa, a violação do direito de propriedade é, em muitas situações, também uma usurpação da posse. Nesses casos, o proprietário pode, além das pretensões fundadas no direito de propriedade, fazer valer também as pretensões relacionadas com a proteção da posse. Desse modo, as pretensões possessórias se colocam em concorrência com as pretensões fundadas no direito de propriedade (BÄHR, 2013, p. 443).

\subsection{A PRETENSÃo DE RESTITUIÇÃo DO PROPRIETÁRIO}

O proprietário pode exigir a restituição da coisa, desde que o possuidor não tenha um direito à posse. A restituição da coisa significa a transmissão da posse pelo até então possuidor ao proprietário. Tal pretensão é uma das mais relevantes do BGB e pode ser considerada a forma mais importante de proteção da propriedade (WOLF; WELLENHOFER, 2019, p. 321). Permite ao proprietário agir contra o possuidor irregular com fundamento no $\S 985$ do BGB (Herausgabeanspruch ou Vindikationsanspruch), que dispõe: "O proprietário pode exigir do possuidor a restituição da coisa" ${ }^{14}$.

O disposto no $\S 985$ do BGB deve, entretanto, ser interpretado em conjunto com o $\S 986$ (Einwendungen des Besitzers), também do BGB (KÜHL; REICHOLD; RONELLENFITSCH, 2019, p. 215). Com isso, o possuidor deve devolver a coisa, a menos que ele esteja exercendo um direito à posse ( $§ 986,1$ do BGB), que pode resultar: a) de uma relação de direito obrigacional entre o proprietário e o possuidor, como, por exemplo, um contrato de locação, previsto no $\S 535$

13 No Brasil, a figura está igualmente presente, falando-se usualmente no sistema da comunhão, cujo exemplo clássico é a comunhão universal de bens existente entre cônjuges (FARIAS; ROSENVALD, 2020, p. 777).

14 Transcrição do texto original do $§ 985$ do BGB: "Der Eigentümer kann von dem Besitzer die Herausgabe der Sache verlangen". 
do BGB (LEIPOLD, 2007, p. 64); b) de um direito real limitado, como é o caso do usufruto (§ 1036 do BGB). Ressalvadas essas situações, que impõem limites à pretensão de restituição, a forma como o possuidor obteve a coisa é irrelevante para o pedido de restituição, uma vez que a propriedade abrange também o direito ao exercício do poder fático sobre a coisa (SCHAPP, 2010, p. 79).

Diferentemente do estabelecido pelo $\S 1007$ do BGB para a pretensão possessória, a restituição ao proprietário não exige que o atual possuidor esteja de má-fé ou que a coisa tenha sido extraviada de alguma forma ou ainda que tenha ocorrido uma privação ilícita da posse. Assim sendo, a pretensão do $\S 985$ do BGB se dirige também contra o ladrão ou mesmo contra aquele que encontrou a coisa (BÄHR, 2013, p. 443).

A partir da interpretação conjunta dos $\S \S 985$ e 986 do BGB resultam as três condições necessárias para a pretensão: a) a propriedade pelo requerente, isto é, o titular da pretensão deve ser proprietário da coisa; b) a posse pela parte contrária, dirigindo-se a pretensão tanto contra $o$ possuidor direto como contra o possuidor indireto; c) o possuidor, perante o proprietário, não pode ter direito de posse ( $§ 986)$ (LEIPOLD, 2007, p. 65).

Por conseguinte, o $\S 985$ apresenta os pressupostos da pretensão a serem demonstrados pelo requerente, enquanto o $\S 986$ contém as objeções, que devem ser provadas pelo réu. Ademais, a pretensão em questão pode ser utilizada tanto pelo proprietário de coisa móvel como de coisa imóvel (KALLWASS; ABELS, 2018, p. 321).

\subsection{ProteÇão CONTRA A TURBAÇÃo da PROPRIEDAdE: PRETENSÃo DE CESSAÇÃo E de OMISSÃo}

O proprietário, como titular de um direito absoluto, não é protegido somente contra a privação da posse. A legislação alemã também prevê proteção contra outras interferências perturbadoras da propriedade (KLINCK, 2018, p. 1271). Entre essas normas, no âmbito do título que cuida das pretensões ligadas à propriedade, está o § 1004, 1 do BGB, que garante ao proprietário a proteção contra qualquer turbação da propriedade que não represente privação ou retenção da posse (MÜLLER; GRUBER, 2016, p. 218).

Nesse contexto, complementando a pretensão de restituição (Herausgabeanspruch), o $\S 1004,1$ do BGB concede ao proprietário dois tipos de pretensão, ou seja, para a cessação (Beseitigungsanspruch) ou para a omissão (Unterlassungsanspruch) de qualquer outra turbação futura que afete o seu direito de propriedade (BAUR; STÜRNER, 2015, p. 137). E considerando a proximidade das pretensões do $\S 1004,1$ do BGB com a actio negatoria do direito romano, ainda hoje as pretensões mencionadas são chamadas de actio negatoria ou de pretensão negatória (negatorischer Anspruch) (WOLF; WELLENHOFER, 2019, p. 390).

Assim sendo, pode-se exigir: a) que uma violação já existente seja reparada a expensas do seu causador (Beseitigung), restaurando-se à situação que existia anteriormente (STAUDINGER; WESTERMANN, 2017, p. 27); b) que futuras turbações à propriedade sejam omitidas (Unterlassung) (BÄHR, 2013, p. 444).

Graças a sua formulação geral, o $\S 1004$ do BGB se aplica a turbações da propriedade móvel e imóvel, no entanto, sua aplicação prática se dá principalmente em relação a imóveis (EISENHARDT, 2018, p. 496).

Desse modo, a pessoa que tem seu direito de propriedade turbado pode exigir a cessação da turbação (Beseitigung), desde que ela continue, isto é, tenha duração (e.g. depositar resíduos em propriedade sem autorização) (KÜHL; REICHOLD; RONELLENFITSCH, 2019, p. 216). Também é requisito para a concessão da pretensão de cessação que a turbação da parte contrária seja ilícita. Se o proprietário está obrigado a tolerar a turbação ao direito de propriedade, como sucede em muitas relações de vizinhança (e.g. pode-se exigir que o vizinho tolere determinados barulhos), a pretensão não é admitida. E os custos para a cessação da turbação devem ser suportados 
pela pessoa que a está causando (LEIPOLD, 2007, p. 65).

Caso o proprietário tema a provocação de novas turbações, isto é, a sua continuidade, tem ele contra o ofensor uma pretensão de omissão (Unterlassung). Tal pretensão objetiva prevenir futuras turbações, demandando os seguintes requisitos: a) uma concreta ameaça de violação de um direito ou um bem jurídico; b) o perigo de repetição de uma interferência ilegal (caso tal interferência já tenha ocorrido) (EISENHARDT, 2018, p. 498).

De fato, qualquer deterioração da propriedade é ilegal, a menos que a parte interveniente esteja autorizada. Existem então situações em que o proprietário deve tolerar a intervenção, o que pode decorrer de um dever de tolerância surgido de uma relação jurídica de direito público ou de direito privado, bem como de uma disposição legal baseada no direito privado ou público ( $§ 1004$, 2 do BGB) (BAUR; STÜRNER, 2015, p. 140).

Em matéria imobiliária, o $\S 906,1$ do BGB fornece mais pormenores, enumerando os principais tipos de turbação (Beeinträchtigung). Referido texto legal trata dos problemas relativos à introdução de gases, vapores, odores, fumaças, fuligem, calor, ruído, trepidações e outras emissões provenientes de um imóvel alheio. Em qualquer caso, a ação deve ser dirigida contra o autor da turbação, ou seja, contra a pessoa que, pelo seu ato, criou a fonte da turbação (FROMONT; KNETSCH, 2017, p. 261).

Por fim, vale notar que o $\S 1004$ do BGB é aplicado analogicamente a todos os outros direitos absolutos, a menos que eles gozem de proteção especial por meio de disposições legais especiais. Aliás, é bastante importante a utilização por analogia da referida norma para a proteção dos bens jurídicos mencionados no $\S 823,1$ do BGB, ou seja, a vida, a saúde, a liberdade e o direito geral da personalidade (EISENHARDT, 2018, p. 497).

\section{CONSIDERAÇÕES FINAIS}

O direito das coisas alemão apresenta peculiaridades bastante importantes, entre as quais, talvez a mais relevante seja a adoção do princípio da abstração, que não encontra correspondência entre os países que seguem a matriz francesa. Esse princípio procura dar maior segurança jurídica nas negociações envolvendo direitos reais, especialmente no que toca à transferência de bens imóveis.

O princípio da separação é pré-requisito para a existência da abstração, isto é, a separação entre direitos obrigacionais e direitos das coisas, o que sucede em alguns ordenamentos jurídicos, como no brasileiro, em que existe a separação, mas não existe a abstração, pelo menos conforme entendimento da doutrina amplamente majoritária. A abstração determina que o negócio jurídico de disposição não depende de causa e sua eficácia permanece inalterada, não obstante o negócio de direito obrigacional se apresentar defeituoso.

Outro aspecto muito relevante do estudo do direito das coisas alemão é a vinculação social desses direitos, que não devem satisfazer apenas as necessidades egoístas do seu titular. O direito de propriedade está assim sujeito a uma obrigação social, de modo que a utilização da propriedade deve também servir ao bem comum, o que está em consonância com os valores de um Estado de direito democrático e social.

Entretanto, ao contrário do defendido por muitos autores no Brasil, na Alemanha a vinculação social da propriedade não integra o próprio conteúdo desse direito. Os estudiosos alemães consideram a vinculação social como um limite ao direito de propriedade. Além disso, a utilização desse princípio pelos tribunais alemães se dá de forma muito mais serena e comedida, o que contrasta com a realidade brasileira, onde muitas decisões judiciais utilizam a função social como um cheque em branco, o que permite, de forma quase que arbitrária, a socialização da propriedade privada. Particularmente nesse ponto, acredita-se que é necessária uma reflexão acerca da segurança jurídica buscada pelo direito alemão, dando limites precisos à vinculação 
social, temática que no Brasil gera grande insegurança aos proprietários.

Por outro lado, o estudo realizado também permitiu se verificar que a forma de proteção do direito de propriedade na Alemanha, apesar dos resultados semelhantes e da inspiração romana, é um pouco diversa da sistemática brasileira. Isso talvez se explique pelo respeito que os tribunais alemães têm pelo BGB, bem como pela adoção da teoria da eficácia horizontal indireta, que suaviza bastante as incursões do direito constitucional sobre o direito civil. E aqui também se impõe uma revisão na forma de atuação no Brasil, visto que muitos tribunais pátrios, fazendo uso de argumentação genérica, não individualizada, aplicam diretamente princípios constitucionais e afastam normas bastante claras e precisas do Código Civil, o que certamente gera grande insegurança nas relações jurídicas.

Por conseguinte, sem negar a forte influência alemã no âmbito do direito das coisas brasileiro, que encampou muitas teorias desenvolvidas por juristas alemães, é inegável que a matéria apresenta pontos de divergência extremamente relevantes entre os dois países. Assim sendo, o presente trabalho procurou traçar um panorama geral do direito das coisas na Alemanha e, ao mesmo tempo, de modo singelo, evidenciar algumas dessas importantes diferenças, que não devem ser olvidadas.

\section{REFERÊNCIAS}

BÄHR, Peter. Grundzüge des Bürgerlichen Rechts. 12. ed. München: Franz Vahlen, 2013.

BAUR, Fritz; STÜRNER, Rolf. Sachenrecht. 18. ed. München: C.H. Beck, 2015.

BREHM, Wolfgang; BERGER, Christian. Sachenrecht. 3. ed. Tübingen: Mohr Siebeck, 2014.

BROX, Hans; WALKER, Wolf-Dietrich. Allgemeiner Teil des BGB. 31. ed. München: Carl Heymanns Verlag, 2007.

CANDIAN, Albina; GAMBARO, Antonio; POZZO, Barbara. Property - Propriété Eigentum. Corso di diritto privato comparato. Padova: CEDAM, 1992.

DECKENBROCK, Christian; HÖPFNER, Clemens. Bürgerliches Vermögensrecht. 3. ed. Baden-Baden: Nomos, 2017.

EISENHARDT, Ulrich. Einführung in das Bürgerliche Recht. 7. ed. Viena: Facultas, 2018.

FARIAS, Cristiano Chaves de; ROSENVALD, Nelson. Curso de direito civil. 16. ed. Salvador: JusPodivm, 2020, v. 5.

FÖRSCHLER, Peter. Grundzüge des Wirtschaftsprivatrechts. München: Franz Vahlen, 2018.

FROMONT, Michel; KNETSCH, Jonas. Droit privé allemand. 2. ed. Paris: LGDJ, 2017.

HUBMANN, Heinrich. Das Persönlichkeitsrecht. 2. ed. Köln: Böhlau, 1967.

KALLWASS, Wolfgang; ABELS, Peter. Privatrecht. 23. ed. München: Franz Vahlen, 2018.

KINGREEN, Thorsten; POSCHER, Ralf. Grundrechte Staatsrecht II. 29. ed. Heidelberg: C.F. Müller, 2013.

KLINCK, Fabian. Sachenrecht. In: STAUDINGER. J. von. J. von Staudingers Kommentar 
zum Bürgerlichen Gesetzbuch mit Einführungsgesetz und Nebengesetzen. Eckpfeiler des Zivilrechts. 6. ed. Berlin: Sellier, 2018. p. 1269-1388.

KLUNZINGER, Eugen. Einführung in das Bürgerliche Recht. 16. ed. München: Franz Vahlen, 2013.

KÜHL, Kristian; REICHOLD, Hermann; RONELLENFITSCH, Michael. Einführung in die Rechtswissenschaft. 3. ed. München: C. H. Beck, 2019.

LEIPOLD, Dieter. BGB I: Einführung und Allgemeiner Teil. 4. ed. Tübingen: Mohr Siebeck, 2007.

LÔBO, Paulo. Direito civil: coisas. 5. ed. São Paulo: Saraiva, 2020. v. 4.

LÔBO, Paulo. Direito civil: parte geral. 7. ed. São Paulo: Saraiva, 2018. v. 1.

LÜKE, Wolfgang. Sachenrecht. 4. ed. München: C. H. Beck, 2018.

MEDER, Stephan; CZELK, Andrea. Grundwissen Sachenrecht. 3. ed. Tübingen: Mohr Siebeck: 2018.

MEDICUS, Dieter. Allgemeiner Teil des BGB. 10. ed. Heidelberg: C.F. Müller, 2010.

MÜLLER, Klaus; GRUBER, Urs Peter. Sachenrecht. München: Franz Vahlen, 2016.

MUSIELAK, Hans-Joachim; HAU, Wolfgang. Grundkurs BGB. 16. ed. München: C. H. Beck, 2019.

PENTEADO, Luciano de Camargo. Direito das coisas. 3. ed. São Paulo: Revista dos Tribunais, 2014.

PIETREK, Marietta. Konsens über Tradition? Tübingen: Mohr Siebeck, 2015.

PRÜTTING, Hanns. Sachenrecht. 36. ed. München: C.H. Beck, 2017.

ROBBERS, Gerhard. Einführung in das deutsche Recht. 6. ed. Baden-Baden: Nomos, 2017.

SCHAPP, Jan. Direito das coisas. Porto Alegre: Sergio Antonio Fabris, 2010.

SCHELLHAMMER, Kurt. Sachenrecht nach Anspruchsgrundlagen. 5. ed. Heidelberg: C.F. Müller, 2017.

SCHWAB, Dieter; LÖHNIG, Martin. Einführung in das Zivilrecht. 20. ed. Heidelberg: C.F.Müller, 2016.

STAUDINGER, Ansgar; WESTERMANN, Harm Peter. Sachenrecht. 13. ed. Heidelberg: C.F. Müller, 2017.

STRACK, Astrid. Hintergründe des Abstraktionsprinzips. Juristische Ausbildung (JURA), Berlin, v. 33, n. 1, p. 5-9, 2011.

TEPEDINO, Gustavo; MONTEIRO FILHO, Carlos Edison do Rêgo; RENTERIA, Pablo. 
Direitos reais. Rio de Janeiro: Forense, 2020.

WITZ, Claude. Le droit allemand. 3. ed. Paris: Dalloz, 2018.

WEBER, Ralph. Sachenrecht: Grundstücksrecht. 4. ed. Baden-Baden: Nomos, 2015, v. II.

WOLF, Manfred; NEUNER, Jörg. Allgemeiner Teil des Bürgerlichen Rechts. 11. ed. München: C.H. Beck, 2016.

WOLF, Manfred; WELLENHOFER, Marina. Sachenrecht. 34. ed. München: C.H. Beck, 2019.

ZANINI, Leonardo Estevam de Assis. Direito Civil: direito das coisas. 2. ed. Rio de Janeiro: Lumen Juris, 2020.

ZANINI, Leonardo Estevam de Assis. O Direito de Superfície na Alemanha e o seu Caráter Social. Mitteilungen der Deutsch-Brasilianischer Juristenvereinigung (DBJV-Mitt.), ano 34, n. 1, p. 39-59, ago. 2016.

Como citar: ZANINI, Leonardo Estevam de Assis. Panorama do direito das coisas na Alemanha. Scientia Iuris, Londrina, v. 25, n. 2, p. 131-150, jul. 2021. DOI: 10.5433/21788189.2021v25n2p131. ISSN: 2178-8189.

Recebido em 19/02/2021

Aprovado em 19/07/2021 